Article

\title{
Preparation of Titania on Stainless Steel by the Spray-ILGAR Technique as Active Photocatalyst under UV Light Irradiation for the Decomposition of Acetaldehyde
}

\author{
Sheela Chandren ${ }^{1, *}$, Kamarulafizam Ismail ${ }^{2}$, Hadi Nur ${ }^{3,4}$ and Bunsho Ohtani ${ }^{5}$ \\ 1 Department of Chemistry, Faculty of Science, Universiti Teknologi Malaysia, UTM JB, 81310 Johor, Malaysia \\ 2 Centre for Biomedical Engineering, Universiti Teknologi Malaysia, UTM JB, 81310 Johor, Malaysia; \\ kamarulafizam@utm.my \\ 3 Centre for Sustainable Nanomaterials, Ibnu Sina Institute for Scientific and Industrial Research, \\ Universiti Teknologi Malaysia, UTM JB, 81310 Johor, Malaysia; hadi@kimia.fs.utm.my \\ 4 Central Laboratory of Minerals and Advanced Materials, Faculty of Mathematics and Natural Science, \\ State University of Malang, Malang 65145, Indonesia \\ 5 Institute of Catalysis, Hokkaido University, Sapporo 001-0021, Hokkaido, Japan; ohtani@cat.hokudai.ac.jp \\ * Correspondence: sheela@utm.my; Tel.: +6012-7655245
}

Received: 31 May 2017; Accepted: 27 June 2017; Published: 6 July 2017

Featured Application: Application of the Spray-ILGAR technique to coat different substrates with titania photocatalyst with the potential for application in various photocatalytic reactions.

\begin{abstract}
One of the methods used to produce buffer layers for thin film solar cells is the Spray ion layer gas reaction (SPRAY-ILGAR). This method has exhibited astonishing efficiencies in the fabrication of homogenous compact metal chalcogenide films. The same approach can be applied in the preparation of photocatalyst on a substrate, in order to acquire a homogeneous and durable layer. In this work, the Spray-ILGAR technique has been utilized in the preparation of titania photocatalysts on stainless steel, which was carried out at Helmholtz-Zentrum Berlin for Materials and Energy, in Berlin, Germany. The characterizations and photocatalytic testing of the synthesized materials were then done at the Institute of Catalysis, Hokkaido University. The scanning electron microscopy (SEM) analysis showed that the titania was dispersed uniformly on top of the stainless steel, with a very durable and strong attachment. It was also found that the concentration of the titania on stainless steel can be easily varied by changing the concentration of the titania-precursor solution. Higher concentrations will result in a more compact and dense layer, while lowering the concentration of the precursor solution produces a less dense layer of $\mathrm{TiO}_{2}$. Apart from that, different temperatures did not change the distribution of the samples much. The photocatalytic activity of the synthesized materials was determined in terms of the photocatalytic decomposition of acetaldehyde under ultra violet (UV) light irradiation. The photocatalytic testing results proved that the samples can completely degrade acetaldehyde under UV irradiation. The heating temperature played a crucial role, as the sample prepared by with heating temperature of $550{ }^{\circ} \mathrm{C}$, concentration of titania-precursor of $6.83 \mathrm{mM}$ and a spraying time of $12 \mathrm{~min}$ showed the best results, requiring only $35 \mathrm{~min}$ to fully degrade 500 ppm of acetaldehyde.
\end{abstract}

Keywords: spray-ILGAR; titania; stainless steel; photocatalytic decomposition; acetaldehyde

\section{Introduction}

Global environmental pollution and destruction are issues of increasing concern in today's society, thus necessitating effective catalysts to degrade harmful pollutants. In recent years, the utilization of 
semiconductors has garnered widespread interest, as a means to induce and improve photocatalytic reactions. A prime example would be metal oxide semiconductor powders, which have exhibited activity when irradiated with ultraviolet (UV) light, and have been widely used as photocatalysts for the degradation of pollutants $[1,2]$. Titania $\left(\mathrm{TiO}_{2}\right)$ has been widely used as a catalyst, due to its many advantageous qualities, namely optical and electronic properties, low cost, high level of photocatalytic activity, chemical stability and non-toxicity [3-5].

Although the most widely used system, $\mathrm{TiO}_{2}$, is usually in nanopowdered-form, as it provides high surface area, filtration is required at the end of a reaction, which complicates the whole process. The other popular form of $\mathrm{TiO}_{2}$, supported $\mathrm{TiO}_{2}$ thin films, on the other hand, mitigates the need for any further post-treatment filtering of the decontaminated fluid, in spite of the limited surface area compared to the dispersed nanoparticle form [6]. Film coatings induce the catalytic properties of $\mathrm{TiO}_{2}$ while taking advantage of the substrate's mechanical properties. There are a number of ways by which $\mathrm{TiO}_{2}$ films are fabricated onto supporting materials (substrates), such as the sol gel method, sputtering technique, electrochemical process, chemical vapour deposition (CVD) and spray pyrolysis [7].

Spray-ILGAR is an extension of the ion layer gas reaction (ILGAR) technique, which was developed and patented by the group of Professor Dr. Christian-Herbert Fischer at the Helmholtz-Zentrum Berlin for Materials and Energy, in Berlin, Germany [8], and which is equivalent to the aerosol assisted chemical vapour depostition (AACVD) method [9]. ILGAR is a non-vacuum, thin-film deposition technique, involving a sequential and cyclic process that enables the deposition of semiconductor thin films, especially chalcopyrite absorber layers and buffer layers. This chemical process permits deposition of layers in a homogenous, adherent and mechanically stable form with the absence of vacuum or high temperatures. This whole process is able to be automated and scaled up. For the case of metal oxides, it usually involves the deposition of an intermediate precursor film (alkoxide), followed by the addition of energy (heating) to chemically convert the precursor to the final product (metal oxide).

In the present work, titania on stainless steel with different concentrations, thicknesses and preparation temperatures was obtained by the aforementioned Spray-ILGAR technique. The photocatalytic activity of the prepared samples was measured in the photocatalytic degradation of gaseous acetaldehyde under UV light irradiation.

\section{Materials and Methods}

\subsection{Preparation of Titania on Stainless Steel}

For the deposition of $\mathrm{TiO}_{2}$, titanium-di-isopropoxide bis(acetylacetonate) $\left(\left(\mathrm{CH}_{3}\right)_{2} \mathrm{CHO}\right)_{2}$ $\left.\mathrm{Ti}\left(\mathrm{C}_{5} \mathrm{H}_{7} \mathrm{O}_{2}\right)_{2}\right)$ (Sigma-Aldrich, St. Louis, MO, USA) was procured from Sigma Aldrich. The precursor solution consisted of $6.83 \mathrm{mM}$ concentration of $\left(\mathrm{C}_{16} \mathrm{H}_{28} \mathrm{O}_{6} \mathrm{Ti}\right)$ dissolved in ethanol p.a. using an ultrasonic device. $\mathrm{TiO}_{2}$ was deposited at a substrate temperature of $460^{\circ} \mathrm{C}$ by using the Ion Layer Gas Reaction, which was carried out in Helmholtz-Zentrum Berlin für Materialien und Energie (HZB), Germany, with a carrier gas $\left(\mathrm{N}_{2}\right)$ flow rate of $5 \mathrm{~L} / \mathrm{min}$. The Spray-ILGAR technique was developed and patented by HZB [9]. The solution was sprayed by an ultrasonic nebulizer, which are transported by the carrier gas (nitrogen) and subsequently deposited on the heated substrate, for $12 \mathrm{~min}$. The substrate was inclined at an angle of $45^{\circ}$ in order to get a homogeneous layer, in order to dramatically minimize turbulence of the aerosol. Experiments conducted using different concentrations of $\mathrm{TiO}_{2}$ precursor (3.42 and $13.66 \mathrm{mM})$, different heating temperature $\left(500\right.$ and $\left.550{ }^{\circ} \mathrm{C}\right)$ and different spraying durations (6 and $24 \mathrm{~min}$ ) were also carried out in order to study their effects on the photocatalytic activity.

\subsection{Characterization}

The thickness of the thin films was evaluated with a Dektak 8 stylus profiler (stylus diamond tip radius $=12.5 \mu \mathrm{m}$, vertical range $=5 \mathrm{~nm}-1 \mathrm{~mm}$, stylus tracking force $=0.03-15 \mathrm{mg}$ ). The morphology of the prepared thin films was investigated with a JEOL JSM-7400F microscope (JEOL, Tokyo, Japan) 
with an acceleration voltage of $3 \mathrm{kV}-6 \mathrm{kV}$. In order to test the strength of adhesion of the $\mathrm{TiO}_{2}$ layer to the stainless steels, the Scotch tape test was carried out, where an adhesive tape was placed on top of the coating. The coating is considered satisfactory and strong if the $\mathrm{TiO}_{2}$ layer remains intact after the removal of the tapes. The crystalline structure of the $\mathrm{TiO}_{2}$ thin film deposited on stainless steel was determined by an X-ray diffractometer (Siemens D5000 XRD unit, Aubrey, TX, USA ) in $2 \theta$ range from 20 to $90^{\circ}$ by $0.07^{\circ} \cdot \mathrm{s}^{-1}$ increasing steps operating at $40 \mathrm{kV}$ accelerating voltage and $40 \mathrm{~mA}$ current using $\mathrm{Cu} \mathrm{K} \alpha$ radiation source with $\lambda=1.5406 \AA$.

\subsection{Photocatalytic Testing}

All the photocatalytic testing in this section was carried out at the Institute of Catalysis, Hokkaido University, Sapporo, Hokkaido, Japan. The photocatalytic activities of the titania on stainless steel were measured by the change in concentration of acetaldehyde as a function of irradiation time. A $100 \mathrm{~mL}$ quartz bottle was used as the reaction vessel, where the coated stainless steel was placed in the bottle, slightly slanted, with maximum surface exposure to the UV light irradiation. Preparation of $500 \mathrm{ppm}$ of acetaldehyde was done in the vessel via injection of saturated gaseous acetaldehyde. The irradiations were conducted at room temperature after equilibrium between the gaseous and adsorbed acetaldehyde had been reached, which is determined via chromatographic monitoring every $30 \mathrm{~min}$. The photoirradiation was carried out in a high-pressure mercury arc, and the temperature was maintained at $25 \pm 0.5^{\circ} \mathrm{C}$ by using a waterbath, equipped with thermostat. After the commencement of the irradiation, the decline in acetaldehyde concentration was evaluated using a gas chromatograph equipped with an FEG-20 M 20\% Celite 545 packed glass column using CR-8A CHROMATOPAC for data processing.

\section{Results and Discussion}

For titania prepared on stainless steel using the Spray-ILGAR technique, the standard procedure is to use titania $\left(\mathrm{TiO}_{2}\right)$ precursor of titanium diisopropoxide bis(acetylacetone) in ethanol with a concentration of $6.83 \mathrm{mM}$, sprayed for $12 \mathrm{~min}$ at a temperature of $460{ }^{\circ} \mathrm{C}$. Using these procedures, the thickness of studied films was determined to be $101 \mathrm{~nm}$. However, this method is usually used for the preparation of solar cells, and not as a photocatalyst. So in order to determine the best condition to prepare a sample with the best photocatalytic activity in the photocatalytic decomposition of air pollutants, the $\mathrm{TiO}_{2}$ on stainless steel was prepared with different concentrations of $\mathrm{TiO}_{2}$-precursor, different heating temperatures, and different durations of spraying time. The thickness of all the samples prepared is presented in Table 1. All of the samples showed similar thickness, in the range of 94-107 $\mathrm{nm}$. Only the sample that had been prepared with $6 \mathrm{~min}$ of spraying time showed a lower thickness of only $75 \mathrm{~nm}$, indicating that the spraying time may have been a bit too short for a thicker layer to form. This shows that the thickness of the $\mathrm{TiO}_{2}$ film on stainless steel was only influenced by the spraying time, and not so much by the concentration of the $\mathrm{TiO}_{2}$ precursor and heating temperature. This is in accordance with the findings of Fischer et al. [8] where they reported that a reasonable time of deposition by ILGAR is needed in order to obtain layers with a maximum thickness of about $100 \mathrm{~nm}$.

The SEM image in Figure 1 shows that the $\mathrm{TiO}_{2}$ prepared by Spray-ILGAR technique using $6.83 \mathrm{mM}$ of $\mathrm{TiO}_{2}$ precursor, heated at $460{ }^{\circ} \mathrm{C}$ and $12 \mathrm{~min}$ of spraying time. The SEM image shows that the $\mathrm{TiO}_{2}$ was dispersed uniformly on top of the stainless steel. Similar morphology has also been reported for $\mathrm{TiO}_{2}$ coated on the surface of glass by the same method [10]. The layer of $\mathrm{TiO}_{2}$ was also very durable, as the attachment was very strong. This was proven by the Scotch Tape test, where the layer of $\mathrm{TiO}_{2}$ remained intact even after removal of the adhesive tapes from the coatings. 
Table 1. Thickness of the $\mathrm{TiO}_{2}$ layers on stainless steels prepared by Spray-ILGAR method by using different concentrations of $\mathrm{TiO}_{2}$ precursor, different heating temperatures and different spraying durations.

\begin{tabular}{ccccc}
\hline Sample & $\begin{array}{c}\text { Concentration of } \\
\mathrm{TiO}_{\mathbf{2}} \text { Precursor }(\mathbf{m M})\end{array}$ & $\begin{array}{c}\text { Heating } \\
\text { Temperature }\left({ }^{\circ} \mathbf{C}\right)\end{array}$ & $\begin{array}{c}\text { Duration of } \\
\text { Spraying (min) }\end{array}$ & Thickness (nm) \\
\hline 1 & 3.42 & 460 & 12 & 94 \\
$2^{*}$ & 6.83 & 460 & 12 & 101 \\
3 & 13.66 & 460 & 12 & 106 \\
4 & 6.83 & 500 & 12 & 99 \\
5 & 6.83 & 550 & 12 & 75 \\
6 & 6.83 & 460 & 6 & 107 \\
7 & 6.83 & 460 & 24 & 03 \\
\hline
\end{tabular}

* The standard parameters used in the preparation of $\mathrm{TiO}_{2}$ layer on substrates by Spray-ILGAR method for the preparation of solar cells.

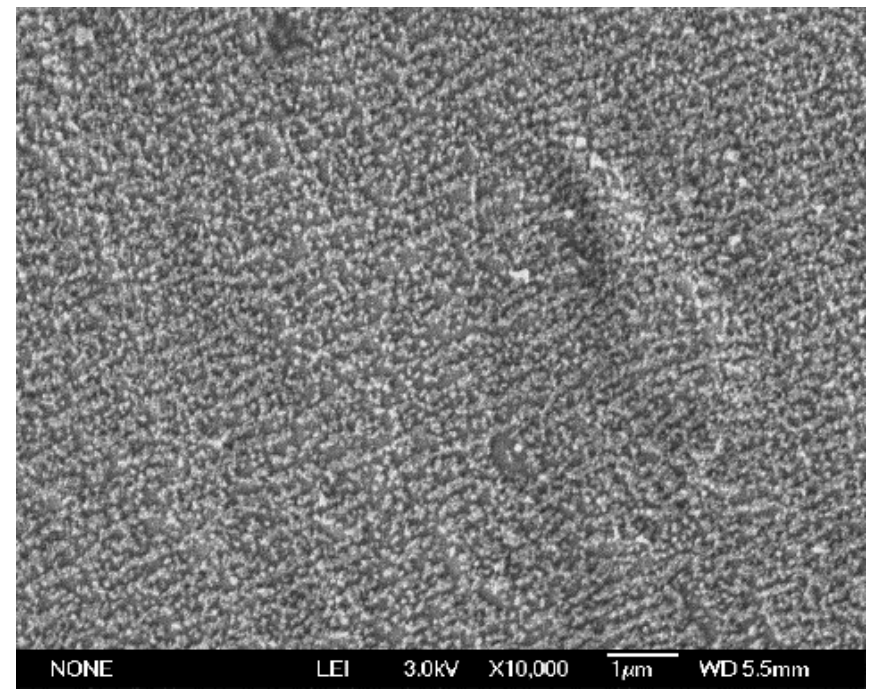

Figure 1. SEM image of $\mathrm{TiO}_{2}$ on stainless steel by Spray-ILGAR technique using $6.83 \mathrm{mM}$ of titanium diisopropoxide bis(acetylacetone) alcoholic solution, heated at $460{ }^{\circ} \mathrm{C}$ and spraying time of $12 \mathrm{~min}$.

The concentration of the $\mathrm{TiO}_{2}$ on the stainless steel can easily be changed by changing the concentration of the $\mathrm{TiO}_{2}$-precursor solution (titanium diisopropoxide bis(acetylacetone) solution). Higher concentrations will result in a more compact and dense layer (Figure 2a). This was further proven by the SEM image was taken at a higher magnification value $(20,000)$, as shown in Figure $2 b$. By lowering the concentration of the precursor solution, a less dense layer of $\mathrm{TiO}_{2}$ was produced (Figure 2c). Some spaces can be seen in between the $\mathrm{TiO}_{2}$ particles when lower concentrations of $\mathrm{TiO}_{2}$ precursor were used, as can be clearly seen in the SEM image with higher magnification (Figure 2d). Using different temperatures did not change the distribution of the samples much.

When the spraying duration was shortened to $6 \mathrm{~min}$, some parts of the stainless steel were uncoated by the $\mathrm{TiO}_{2}$ (Figure 3a). This is most probably caused by insufficient spraying time for the layer to form [8]. The thickness measurement also supports this hypothesis. As for the sample prepared by using 24 min of spraying time, a nice dense and compact layer of $\mathrm{TiO}_{2}$ was formed (Figure 3b). 


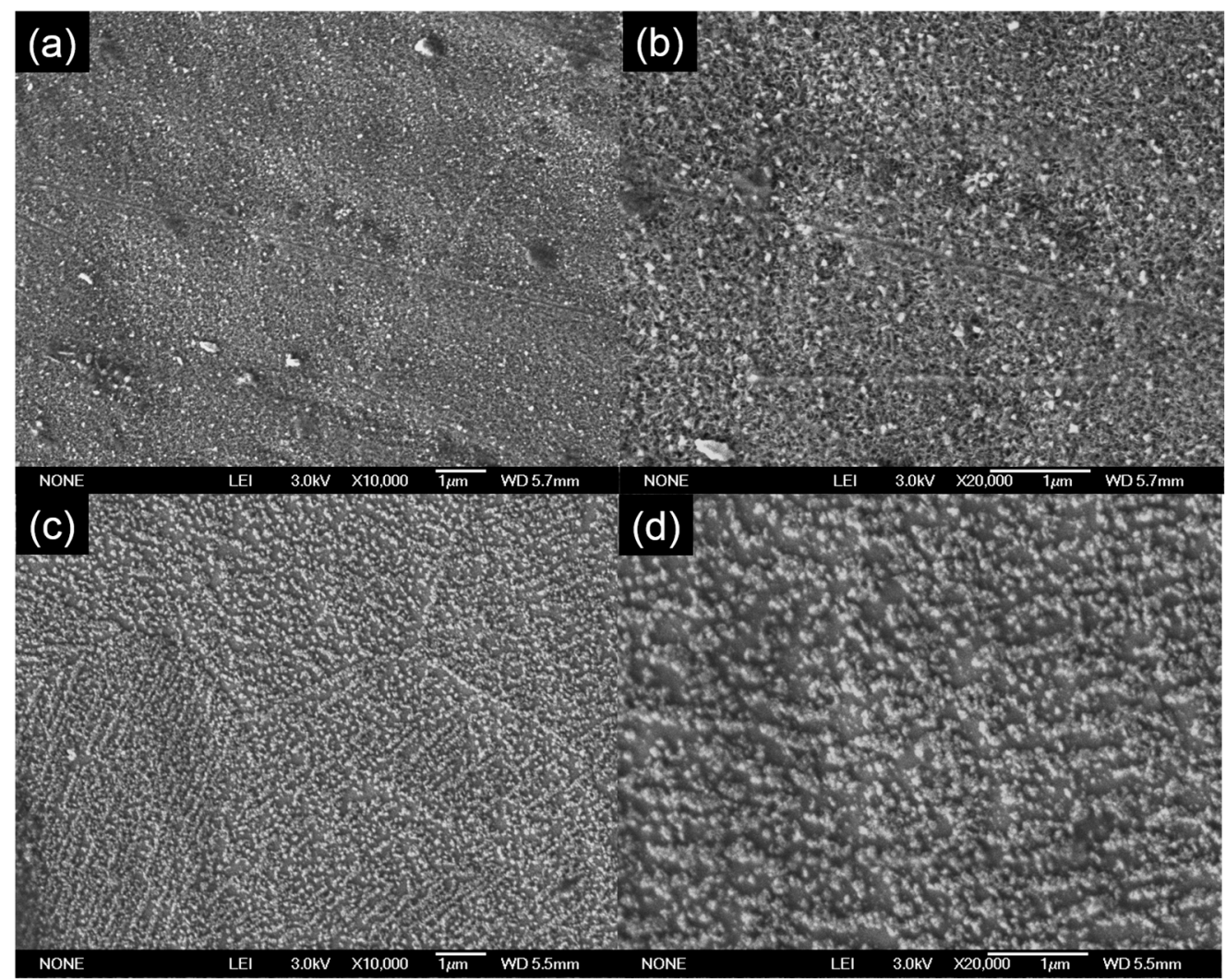

Figure 2. SEM images of $\mathrm{TiO}_{2}$ on stainless steel using higher concentration (13.66 mM) ((a) and (b)) and lower concentration $(3.42 \mathrm{mM})((\mathbf{c})$ and $(\mathbf{d}))$ of titanium diisopropoxide bis(acetylacetone) alcoholic solution. The spraying duration used was $12 \mathrm{~min}$ and heating temperature of $460{ }^{\circ} \mathrm{C}$.

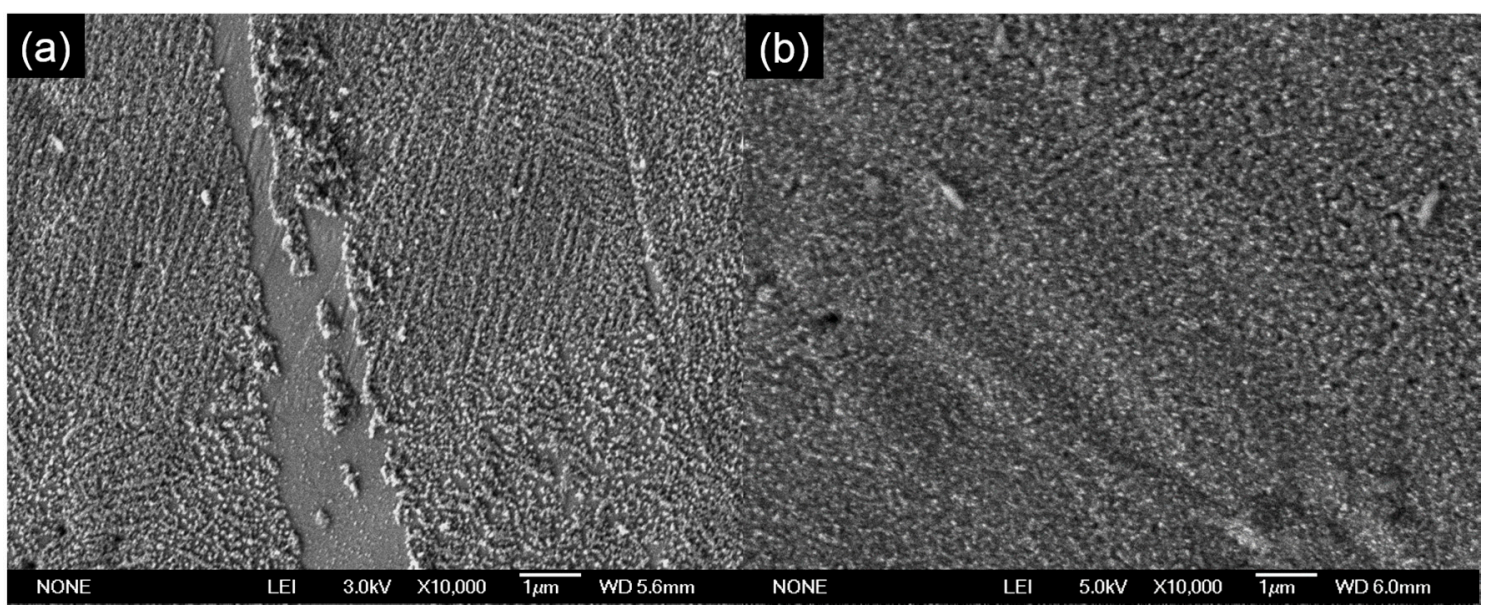

Figure 3. SEM images of $\mathrm{TiO}_{2}$ on stainless steel by Spray-ILGAR technique using $6.83 \mathrm{mM}$ of $\mathrm{TiO}_{2}$ precursor, heating temperature of $460{ }^{\circ} \mathrm{C}$ and (a) shorter spraying time (6 min) and (b) longer spraying time (24 min).

Figure 4 shows the XRD pattern for the prepared titania on stainless steel by Spray-ILGAR method. However, only a small peak corresponding to the (101) reflection of anatase $\mathrm{TiO}_{2}$ at $2 \theta$ value of around $25^{\circ}$ can be detected. The rest of the diffraction peaks are attributed to the stainless steel substrate [11]. This could be caused by the small amount and thin layer of $\mathrm{TiO}_{2}$ present in the sample. As no further analysis using XRD was carried out, no conclusive results can be drawn from the XRD analysis. 


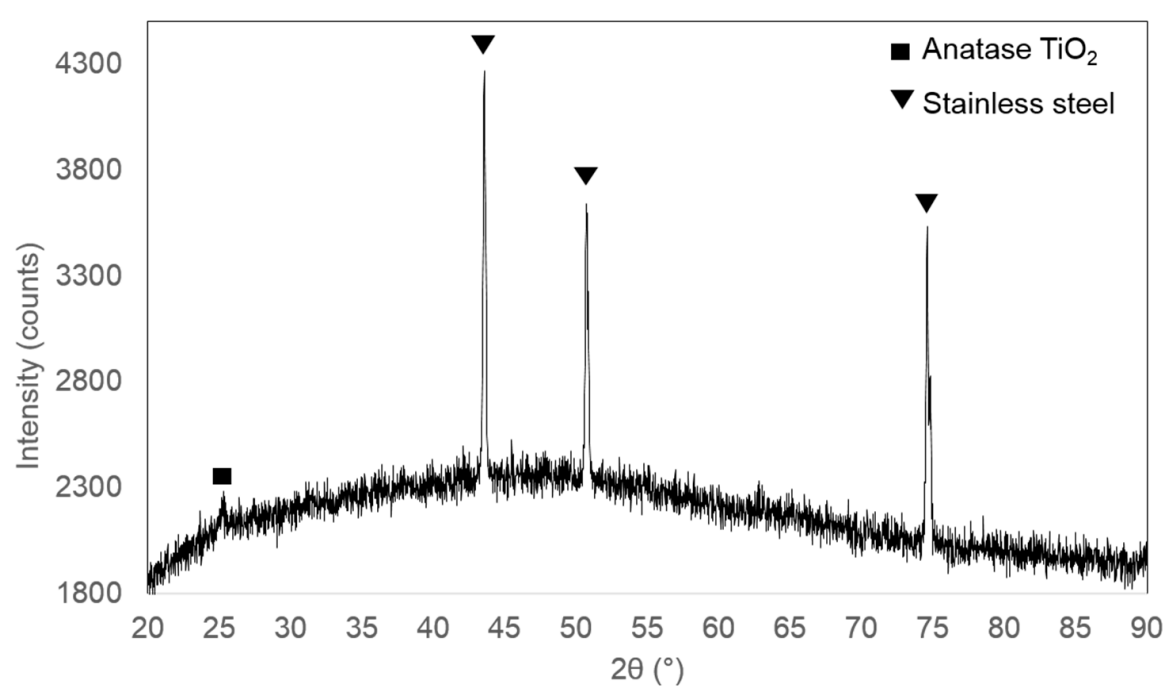

Figure 4. XRD pattern of $\mathrm{TiO}_{2}$ coated on stainless steel by Spray-ILGAR technique using $6.83 \mathrm{mM}$ of titanium diisopropoxide bis(acetylacetone) alcoholic solution and heated at $460^{\circ} \mathrm{C}$.

The photocatalytic results of the samples using different concentrations of $\mathrm{TiO}_{2}$ precursor, different heating temperature and different duration of spraying time are summarized in Table 2. Based on the results, it was found that sample prepared with concentration of $\mathrm{TiO}_{2}$ precursor of $6.83 \mathrm{mM}$, temperature of $550{ }^{\circ} \mathrm{C}$ and spraying time of $12 \mathrm{~min}$ took the shortest time (35 min) to completely degrade $500 \mathrm{ppm}$ of acetaldehyde under UV irradiation. It would seem that out of the three parameters studied, the heating temperature played a slightly more important role. This could be caused by the crystallinity of the $\mathrm{TiO}_{2}$ as the crystallinity of a photocatalyst influences the charge recombination rate and, consequently, on the photocatalytic activity [12]. However, as the crystallinity could not be properly determined using the XRD analysis carried out, this hypothesis could not be confirmed.

Table 2. Photocatalytic decomposition of acetaldehyde by using $\mathrm{TiO}_{2}$ on stainless steel prepared by Spray-ILGAR technique using different concentrations of $\mathrm{TiO}_{2}$ precursor, different heating temperatures and different spraying durations.

\begin{tabular}{ccccc}
\hline Sample & $\begin{array}{c}\text { Concentration of } \\
\mathbf{T i O}_{2} \text { Precursor (mM) }\end{array}$ & $\begin{array}{c}\text { Heating } \\
\text { Temperature }\left({ }^{\circ} \mathbf{C}\right)\end{array}$ & $\begin{array}{c}\text { Duration of } \\
\text { Spraying (min) }\end{array}$ & $\begin{array}{c}\text { Time Required to Fully Degrade } \\
\text { 500 ppm of Acetaldehyde under } \\
\text { UV Irradiation (min) }\end{array}$ \\
\hline 1 & 3.42 & 460 & 12 & 700 \\
$2^{*}$ & 6.83 & 460 & 12 & 90 \\
3 & 13.66 & 460 & 12 & 40 \\
4 & 6.83 & 500 & 12 & 90 \\
5 & 6.83 & 550 & 12 & 85 \\
6 & 6.83 & 460 & 6 & 50 \\
7 & 6.83 & 460 & 24 & 500 \\
\hline
\end{tabular}

* The standard parameters used in the preparation of $\mathrm{TiO}_{2}$ layer on substrates by Spray-ILGAR method for the preparation of solar cells.

Apart from the heating temperature, the concentration of the $\mathrm{TiO}_{2}$ precursor also seems to play a crucial role, as the sample prepared with a concentration of $\mathrm{TiO}_{2}$ precursor of $13.66 \mathrm{mM}$, temperature of $460^{\circ} \mathrm{C}$ and spraying time of $12 \mathrm{~min}$ took the second shortest time ( $40 \mathrm{~min}$ ) to completely degrade $500 \mathrm{ppm}$ of acetaldehyde under UV irradiation. As discussed in the morphology analysis, samples prepared with higher concentration of the $\mathrm{TiO}_{2}$ precursor showed a more compact and dense layer (Figure 2a,b). This would indicate that more $\mathrm{TiO}_{2}$ (active sites) are available to be used in the photodegradation of acetaldehyde, hence the shorter time required. 
Figure 5 shows the graph for the photocatalytic decomposition of acetaldehyde by using $\mathrm{TiO}_{2}$ on stainless steel prepared by the Spray-ILGAR technique using different concentrations of $\mathrm{TiO}_{2}$ precursor $(3.42,6.83$ and $13.66 \mathrm{mM})$, heated at $460{ }^{\circ} \mathrm{C}$ and spraying time of $12 \mathrm{~min}$. As expected, the sample prepared with $\mathrm{TiO}_{2}$ precursor with concentration of $3.42 \mathrm{mM}$ showed the slowest decomposition rate. The highest photodecomposition rate was shown by the sample prepared with $\mathrm{TiO}_{2}$ precursor with concentration of $6.83 \mathrm{mM}$, instead of that by the sample prepared using $13.66 \mathrm{mM}$ of $\mathrm{TiO}_{2}$ precursor. As shown in the SEM results (Figure $2 \mathrm{a}, \mathrm{b}$ ), the sample prepared with $13.66 \mathrm{mM}$ of $\mathrm{TiO}_{2}$ precursor showed a very compact and dense layer. The compactness would have caused a decrease in the surface area, hence the lower photodecomposition rate.

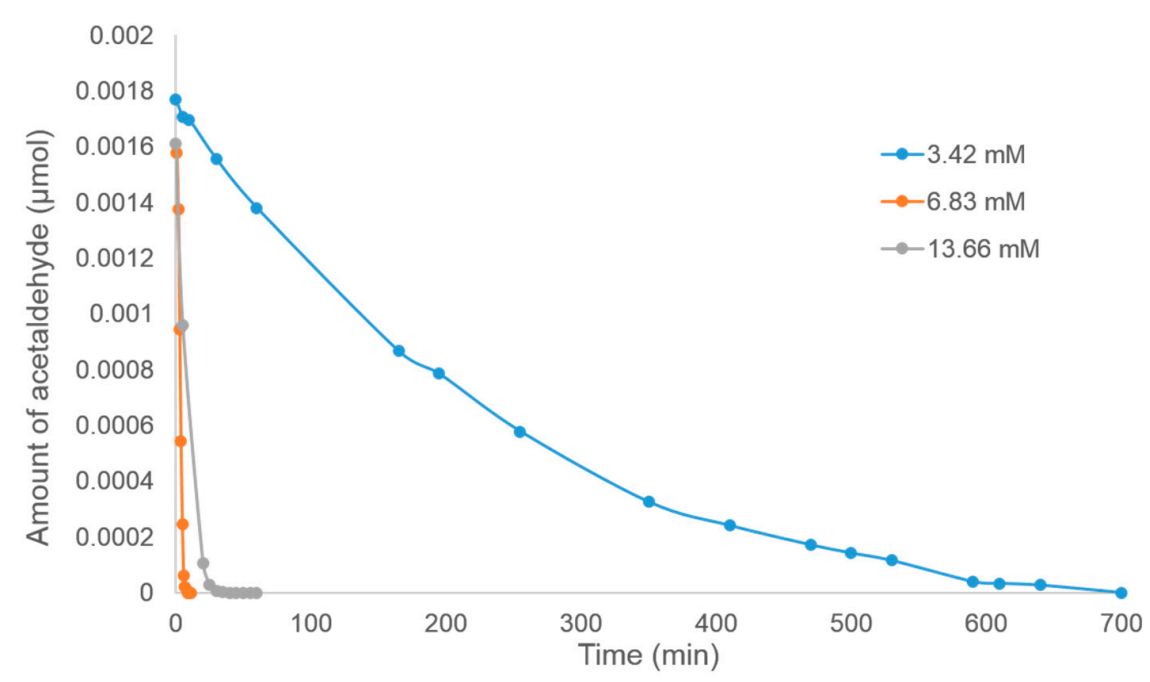

Figure 5. Photocatalytic decomposition of acetaldehyde by using $\mathrm{TiO}_{2}$ on stainless steel prepared by Spray-ILGAR technique using different concentrations of $\mathrm{TiO}_{2}$ precursor $(3.42,6.83$ and $13.66 \mathrm{mM})$, heated at $460{ }^{\circ} \mathrm{C}$ and spraying time of $12 \mathrm{~min}$.

Figure 6 shows the graph for the photocatalytic decomposition of acetaldehyde by using $\mathrm{TiO}_{2}$ on stainless steel prepared by the Spray-ILGAR technique using different heating temperatures $(460,500$ and $\left.550{ }^{\circ} \mathrm{C}\right), 6.83 \mathrm{mM}$ of $\mathrm{TiO}_{2}$ precursor and spraying time of $12 \mathrm{~min}$. It was shown that the higher the heating temperature, the faster the decomposition rate. As discussed above, the possible cause for this could be caused by the crystallinity of the $\mathrm{TiO}_{2}$. However, as the crystallinity could not be properly determined using XRD analysis carried out, the reason remains a hypothesis.

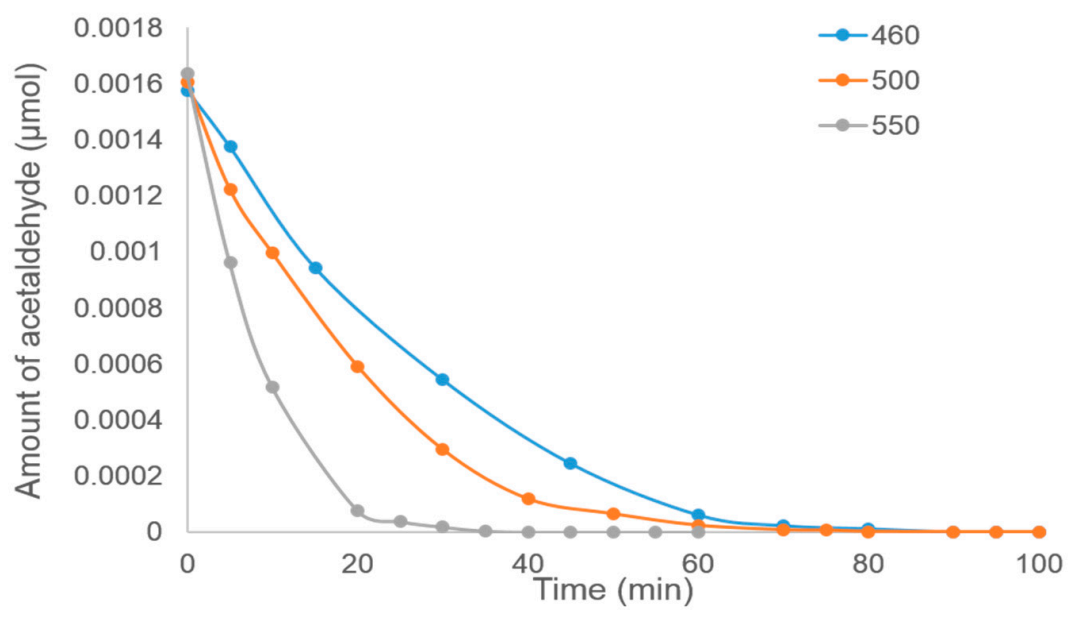

Figure 6. Photocatalytic decomposition of acetaldehyde by using $\mathrm{TiO}_{2}$ on stainless steel prepared by Spray-ILGAR technique using different heating temperatures $\left(460,500\right.$ and $\left.550{ }^{\circ} \mathrm{C}\right), 6.83 \mathrm{mM}^{\circ} \mathrm{TiO}_{2}$ precursor and 12 min of spraying time. 
The photocatalytic decomposition of acetaldehyde by using $\mathrm{TiO}_{2}$ on stainless steel prepared by the Spray-ILGAR technique using different spraying durations (6, 12 and $24 \mathrm{~min}), 6.83 \mathrm{mM}$ of $\mathrm{TiO}_{2}$ precursor and heating temperature of $460^{\circ} \mathrm{C}$ is shown in Figure 7. Based on the graph, it can be seen that the sample prepared using 24 min of spraying time showed the highest photodecomposition rate, while the slowest was shown by the sample prepared using $6 \mathrm{~min}$ of spraying time. This pattern was expected, as when the sample was prepared using $24 \mathrm{~min}$ of spraying time, a dense and compact layer of $\mathrm{TiO}_{2}$ was formed (Figure 3b), hence providing more $\mathrm{TiO}_{2}$ to act as the photocatalyst. However, when the spraying time was decreased to only $6 \mathrm{~min}$, a very thin layer resulted (Table 1), and some parts of the stainless steel were also uncoated (Figure 3a).

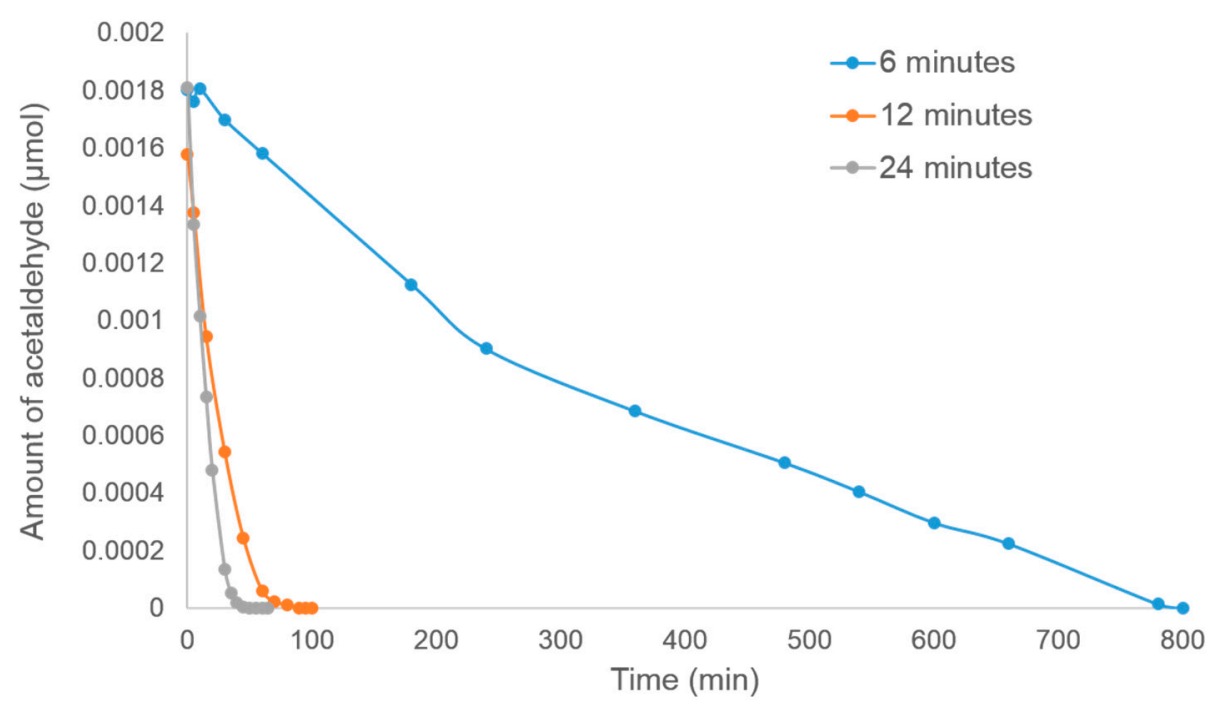

Figure 7. Photocatalytic decomposition of acetaldehyde by using $\mathrm{TiO}_{2}$ on stainless steel prepared by Spray-ILGAR technique using different spraying durations $(6,12$ and $24 \mathrm{~min}), 6.83 \mathrm{mM}^{\text {of }} \mathrm{TiO}_{2}$ precursor and heating temperature of $460{ }^{\circ} \mathrm{C}$.

\section{Conclusions}

A strong and durable layer of titania was successfully attached on the surface of stainless steel by employing the Spray-ILGAR technique. The concentration of the titania on the stainless steel can be easily varied by changing the concentration of the titania-precursor solution. Higher concentrations will result in a more compact and dense layer, while lowering the concentration of the precursor solution produces a less dense layer of $\mathrm{TiO}_{2}$. The spraying duration employed also changes the distribution of the $\mathrm{TiO}_{2}$ on the stainless steel, where a shorter spraying time caused some parts of the substrate to be uncoated, while longer spraying time allowed the formation of a dense and compact $\mathrm{TiO}_{2}$ layer. In the photocatalytic degradation of acetaldehyde, out of the three parameters studied, the heating temperature was the most crucial, as the sample prepared with a heating temperature of $550{ }^{\circ} \mathrm{C}$, concentration of titania-precursor of $6.83 \mathrm{mM}$ and spraying time of $12 \mathrm{~min}$ showed the best results, requiring only $35 \mathrm{~min}$ to fully degrade $500 \mathrm{ppm}$ of acetaldehyde. This shows that, apart from being used to prepare solar cells, the Spray-ILGAR technique can also be applied effectively in the preparation of photocatalyst thin films.

Acknowledgments: The authors gratefully acknowledge funding from Universiti Teknologi Malaysia under Potential Academic Staff (Q.J130000.2726.02K50), Ministry of Education Malaysia under the Long Term Research Grant Scheme (R.K130000.7340.4L825), Japan Student Services Organization (JASSO) under Follow-up Research Fellowship for Former International Students and DAAD (Deutscher Akademischer Austauschdienst) under German Academic Exchange Service. 
Author Contributions: All the experimental work was performed by Sheela Chandren. The experimental work carried out in HZB was conceived and designed by Sheela Chandren and Hadi Nur, while Sheela Chandren and Bunsho Ohtani conceived and designed the experiments carried out in Hokkaido University. Sheela Chandren and Kamarulafizam Ismail wrote the paper.

Conflicts of Interest: The authors declare no conflict of interest.

\section{References}

1. Zhang, Y.; Xu, Q.; Lamson, J.J.; Zhao, R. Photocatalytic purification of volatile organic compounds in indoor air: A literature review. Atmos. Environ. 2009, 43, 2229-2246.

2. Taranto, J.; Frochot, D.; Pichat, P. Combining cold plasma and $\mathrm{TiO}_{2}$ photocatalysis to purify gaseous effluents: A preliminary study using methanol-contaminated air. Ind. Eng. Chem. Res. 2007, 46, 7611-7614. [CrossRef]

3. Lee, R.; Kumaresan, Y.; Yoon, S.Y.; Um, S.H.; Kwon, I.K.; Jung, G.Y. Design of gold nanoparticles-decorated $\mathrm{SiO}_{2} @ \mathrm{TiO}_{2}$ core/shell nanostructures for visible light-activated photocatalysis. RSC Adv. 2017, 7, 7469-7475. [CrossRef]

4. Thompson, T.L.; Yates, J.T. Surface science studies of the photoactivation of $\mathrm{TiO}_{2}$ new photochemical processes. Chem. Rev. 2006, 106, 4428-4453. [CrossRef] [PubMed]

5. Ollis, D.F.; Pelizzetti, E.; Serpone, N. Photocatalyzed destruction of water contaminants. Environ. Sci. Technol. 1991, 25, 1522-1529. [CrossRef]

6. Bestetti, M.; Sacco, D.; Brunella, M.F.; Franz, S.; Amadelli, R.; Samiolo, L. Photocatalytic degradation activity of titanium dioxide sol-gel coatings on stainless steel wire meshes. Mater. Chem. Phys. 2010, 124, 1225-1231. [CrossRef]

7. Carp, O.; Huisman, C.L.; Reller, A. Photoinduced reactivity of titanium dioxide. Prog. Solid State Chem. 2004, 32, 33-177. [CrossRef]

8. Fischer, C.H.; Muffler, H.J.; Bär, M.; Kropp, T.; Schönmann, A.; Fiechter, S.; Lux-Steiner, M.C. Spray-ion layer gas reaction (ILGAR): A novel low-cost process for the deposition of chalcopyrite layers up to the micrometer range for photovoltaic applications. J. Phys. Chem. B 2003, 107, 7516-7521. [CrossRef]

9. Fischer, C.H.; Allsop, N.A.; Gledhill, S.E.; Köhler, T.; Krüger, M.; Sáez-Araoz, R.; Fu, Y.; Schwieger, R.; Richter, J.; Wohlfart, P.; et al. The spray-ILGAR®(ion layer gas reaction) method for the deposition of thin semiconductor layers: Process and applications for thin film solar cells. Sol. Energy Mater. Sol. Cells 2011, 95, 1518-1526. [CrossRef]

10. Ennaceri, H.; Erfurt, D.; Wang, L.; Köhler, T.; Taleb, A.; Khaldoun, A.; Ennaoui, A. Deposition of multifunctional $\mathrm{TiO}_{2}$ and $\mathrm{ZnO}$ top-protective coatings for CSP application. Surf. Coat. Technol. 2016, 298, 103-113. [CrossRef]

11. Adraider, Y.; Pang, Y.X.; Nabhani, F.; Hodgson, S.N.; Sharp, M.C.; Al-Waidh, A. Photocatalytic activity of titania coatings synthesised by a combined laser/sol-gel technique. Mater. Res. Bull. 2014, 54, 54-60. [CrossRef]

12. Meire, M.; Verbruggen, S.W.; Lenaerts, S.; Lommens, P.; Van Der Voort, P.; Van Driessche, I. Microwave-assisted synthesis of mesoporous titania with increased crystallinity, specific surface area, and photocatalytic activity. J. Mater. Sci. 2016, 51, 9822-9829. [CrossRef] 